\title{
Ergenlerde Gözlenen Boyun Eğiciliğin Onların Kişiler Arası Problem Çözme Yaklaşımları Ửzerindeki Etkisi ${ }^{1}$
}

\author{
Ahmet Selçuk YILMAZ² ve Mehmet Engin DENIZ ${ }^{3}$
}

Öz

Yapılan araştırmanın amacı; ergenlerde gözlenen boyun eğici davranışların onların problem çözme yaklaşımları üzerindeki etkisi sınamaktır. İlişkisel tarama yönteminin kullanıldığ1 çalışmaya \%56,7’si kız, \%43,3’ü erkek 763 ortaöğretim öğrencisi katılmıştır. Veri toplama aracı olarak Kişiler arası Problem Çözme Envanteri ve Ergen Boyun Eğicilik Ölçeği kullanılmış, verilerin analizinde yapısal eşitlik modellemesi yöntemi kullanılmıştır. Araştırmanın sonunda ergen boyun eğiciliği ile problem çözme yaklaşımları arasında pozitif anlamlı ilişki gözlenmiştir $(\beta=.474$; $\mathrm{p}<.05)$. Ergen boyun eğiciliğinin problem çözme yaklaşımları puanlarındaki toplam değişimin \%22'sini açılklamaktadır. Bununla birlikte; ergen boyun eğiciliği problemlere olumsuz yaklaşımın $(\beta=.582 ; \mathrm{p}<.05)$, kendine güvensizliğin $(\beta=.687 ; \mathrm{p}<.05)$ ve sorumluluk almamanın $(\beta=.351 ; \mathrm{p}<.05)$ anlamlı yordayıcısıdır. Buna karşılık ergen boyun eğiciliğinin 1srarcı-sebatkar yaklaşımı $(\beta=-.009 ; p>.05)$ ve yapıc1 problem çözmeyi $(\beta=-.039 ; p>.05)$ anlamlı düzeyde yordamadığ1 görülmüştür.

Anabtar Kelimeler: Ergenlik, Boyun eğicilik, Problem çözme yaklaşımları

\section{The Effect of Submissiveness Observed Among Adolescents on Solving Interpersonal Problems}

\section{Abstract}

Purpose of the study is to check the effect of submissive behavior observed in adolescents on their approaches to solving problems. 763 secondary school pupils (56.7\% female and 43.3\% male) participated in the research which was done by the relational screening method. Interpersonal Problem-Solving Inventory and Adolescent Submissiveness Scale were used to collect data and to analyze them they used structural equation modeling method. At the end of the study, a positive relationship was observed between adolescent submissiveness and problemsolving approaches $(\beta=.474 ; \mathrm{p}<.05)$. Adolescent submissiveness is $22 \%$ out of the total change in problem-solving approach scores Nevertheless, adolescence submissiveness is a significant predictor of a negative approach to problems $(\beta=.582 ; \mathrm{p}<.05)$, self-confidence $(\beta=.687 ; \mathrm{p}<.05)$, and lack of responsibility $(\beta=.351 ; \mathrm{p}<.05)$. However, it was seen that adolescent submissiveness did not significantly predict insistent-persistent approach $(\beta=-$ $.009 ; \mathrm{p}>.05)$ and constructive problem-solving $(\beta=-.039 ; \mathrm{p}>.05)$.

Key Words: Adolescence, Submissive behaviors, Problem solving approaches

\section{Atıf İçin / Please Cite As:}

Yılmaz, A. S. ve Deniz, M. E. (2020). Ergenlerde gözlenen boyun eğiciliğin onların kişiler arası problem çözme yaklaşımları üzerindeki etkisi. Manas Sosyal Araștırmalar Dergisi, 9(2), 684-694.

Geliş Tarihi / Received Date: 20.11.2019

Kabul Tarihi / Accepted Date: 27.12.2019

\footnotetext{
${ }^{1}$ Makale Yıldız Teknik Üniversitesi Eğitim Bilimleri Enstitüsünde Prof. Dr. Mehmet Engin Deniz Danışmanlığında Ahmet Selçuk Yılmaz tarafindan yapılan doktora tezinden üretilmiştir.

${ }^{2}$ Uz. Psikolojik Danışman. MEB - Ahmet Hazım Uluşahin İmam Hatip Ortaokulu, ahmetselcukyilmaz@yahoo.com ORCID: 0000-0003-1148-4496

3 Prof. Dr.- Yıldız Teknik Üniversitesi, Eğitim Fakültesi, edeniz@yildiz.edu.tr ORCID: 0000-0002-7930-3121
} 


\section{Giriş}

İnsanlarda üç tür davranıș özelliği gözlenmektedir. Bir uçta boyun eğici davranış varken, diğer uçta saldırgan davranış yer alır. Bu iki davranış tipinin ortasında ise hakkını koruyan ve sahip çıkan bir davranış örüntüsü yer alır. Boyun eğici davranış aynı zamanda pasif ve çekingen davranış olarak da ele alınmıştır (Tuzcuoğlu ve Korkmaz, 2001, s. 135-152; Dönmez ve Demirtaş, 2009, s. 445-456). Boyun eğme teknik bir terim olarak Milgram'in (1974, s. 58-61) çalısmaları ile psikolojide popüler hale gelmiştir. Boyun eğme, bireysel davranışı güçsel kararlılığa bağlayan psikolojik mekanizmadır, insanları otoriteye bağlayan eğilimsel bağlllıktır. Günlük yaşama ait vaka hikâyeleri gösterir ki; birçok insan için, boyun eğmek yoğun olarak yerleşmiş bir davranış eğilimidir ve etik, anlayış ve ahlaki davranışlar üzerinde aşırı eğitimin sonucu oluşan bir iç tepkidir.

Boyun eğici davranışlar, başkalarını kırmamaya ve incitmemeye özen gösteren, herkesi memnun etmeye çalışan ve iyiliksever olmaya eğilimli, hayır demekten çekinen, hoşlanmadığı durumları ifade etmekte ve öfkesini göstermekte zorluk çeken, sürekli onaylanma gereksinimi duyan, düşüncelerini ve haklarını savunamayan ve benzeri davranışlarla gözlenebilen bir kişilik özelliği kümesi olarak tanımlanmaktadır (Gilbert ve Steven, 1994: 295-306). İnsanların boyun eğici davranış göstermelerindeki en önemli kaynağın otoriter, disiplinli, denetimli, baskıcı, aşırı kısıtlayıcı anne ve baba tutumları olduğunu belirtmiştir. Aşırı baskı ile yetişen bireylerde genellikle içe kapanık veya boyun eğici davranış sergilemektedirler (Tekin ve Filiz, 2008, s. 27-37; Gander ve Gardiner, 1998, s. 126-140; Tuzcuoğlu ve Korkmaz, 2001, s. 135-152). Mackinnon, Henderson ve Andrewese (1992, s. 135-140) ebeveynlerin çocuklarını büyüme niteliklerini görmezlikten gelerek davranmaları, psikolojik gereksinimlerini karşılamamaları ve çocuğu sıklıkla kontrol altında tutarak boyun eğici davranmaya mecbur bırakmalarının, çocuklarda bir takım psikolojik zarara sebebiyet verdiği ifade etmiştir. Boyun eğici davranışların kazanılmasında anne babaların birinci derecede sorumlu olmalarının yanında öğretmenlerin, ögrencilere yaklaşımlarının ve onlarla kurdukları iletişim biçimlerinin de etkili olduğunu, en azından öğretmen yaklaşımlarının bu davranışların sürdürülmesine ya da bırakılmasına etki edeceğini söylemek yanlış olmayacaktır.

Bireylerin boyun eğici tutumlar sergilemek zorunda kalmaları ruh sağlikl1lığı yönünden bazı olumsuz etkiler ortaya çıkarmaktadır ve bu durum depresyon ile doğrudan ilişkilidir (Koç, Bayraktar ve Çolak, 2010, s. 257-280). Aynı zamanda boyun eğici davranışlar bireyin bilişsel, duyuşsal ve davranışsal becerileri kazanmasını etkilemekte ve sosyal yaşam için gerekli olan paylaşma, iş birliği ve sorumluluk gibi özellikleri kazanmasını engellemektedir (Tümkaya, Çelik ve Aybek, 2011, s. 77-94).

Boyun eğicilik ile çok sayıda değişken arasında ilişki arayan araştırmalar yapılmış olmasına karşılık kişiler arası problem çözme yaklaşımları ile boyun eğicilik arasındaki ilişkiyi sınayan araştırmaya rastlanmamıştır. Özellikle ergenlerde gözlenen boyun eğiciliğin onların problem çözme yaklaşımları üzerindeki etkisi henüz ele alınmamış bir konudur. Yapılan araştırmanın bu açıdan özgün olduğu ve alana katk1 yapacağı umulmaktadır.

Kişilerarası problem, İki veya daha fazla insanın ilişkisinde oluşan davranışsal isteklerin veya beklentilerin engellenmesi durumunda ortaya çıkan bir çelişki olarak tanımlanmıştı (Jacobson ve Margolin 1979, s. 81-90). Bu bağlamda, kişilerarası problem çözme, ilgili tüm taraflar için kabul edilebilir veya tatmin edici olan çözümünü tanımlamayı, çatışmanın ortadan kalkmasını sağlayan ve keşfetmeyi amaçlayan bilişsel bir kişilerarası süreç olarak tanımlanabilir.

Problem çözme, bir birey, çift ya da grubun, bir problem karşısında etkili çözümler tanımlamasını ve bu çözümlerden uygun olanı seçmesini kapsayan bilişsel ve davranışsal süreçtir. Isaksen ve Aerts (2011, s. 7-38) problem çözmeyi, genellikle soruları cevaplayan, bireyin sahip oldukları ile arzu ettikleri arasındaki boşluğu kapatmayı gerektiren, zorluk arz eden buna karşıllk yeni firsatlar sunan ve bazı endişe verici bir durumla karşılaşılması durumda tatmin edici yolları tasarlamayı içeren bir süreç olarak tanımlamışlardır.

Kişiler arası problemin farkında olan birey, mevcut durumla erişilmek istenen amacın yol açtı̆̆ gerginlikten kurtulmak için farklı yollara başvurur. Birçok araştırmacı, kişiler arası problem çözme yaklaşımları olarak isimlendirilen bu yöntemleri çeşitli şekillerde sınıflandırmışlardır. Yapılan araştırmada Çam ve Tümkaya'nın (2007, s. 95-111; 2008, s. 1-17) yaptığı sınıflama temel alınmıştır. Yazarlar kişilerarası problem çözmeyi; Probleme olumsuz yönelme, yapıcı problem çözme, kendine güvensizlik, sorumluluk almama ve ısrarcı-sebatkâr yaklaşım olarak boyutlandırmıştır. 
Probleme olumsuz yaklaşım, kişilerarası bir problemle karşı karşıya kalındığında yaşanan çaresizlik, karamsarlık ve hissedilen üzüntü gibi ağır olumsuz duygu ve düşüncelerle ilgilidir. Yapıcı problem çözme, kişilerarası bir sorun yaşandığında kişilerin etkili ve yapıcı biçimde problemi çözmesine katkı sunan duygu, düşünce ve davranışlarla ilişkilidir. Israrcı-sebatkâr yaklaşım kişinin kişilerarası ilişkilerinde problem çözümü için ısrarlı bir şekilde çaba harcamayı ortaya koymaktadır. Kendine güvensiz yaklaşım ise, herhangi bir problemi çözebilme konusunda kişinin sahip olduğu güven eksikliğini ifade ederken, sorumluluk almama ise; problem çözme konusundaki sorumluluk almamayı ifade etmektedir (Çam ve Tümkaya, 2007, s. 95-111).

Yapılan çalışmada ergenlerde gözlenen boyun eğici davranışların onların yukarıda sayılan problem çözme yaklaşımları üzerindeki etkisi sınanmıştır. Bu amaçla aşağıdaki sorulara cevaplar aranmıştır.

1. Ergen boyun eğiciliği problem çözme yaklaşımlarının toplamını (genelini) ne düzeyde açıklamaktadır?

2. Ergen boyun eğiciliği problem çözme yaklaşımlarının alt boyutlarını (Probleme Olumsuz Yaklaşma, Yapıcı Problem Çözme, Kendine Güvensizlik, Sorumluluk Almama ve Israrcı-Sebatkâr Yaklaşım) ne düzeyde açıklamaktadır?

\section{Yöntem}

Araştırmada ilişkisel tarama yöntemi kullanılmıştır. Bu yöntem iki ve daha çok sayıdaki değişken arasında birlikte değişim varllğını veya derecesini belirlemeyi amaçlar (Karasar, 2005, s. 46-50). Aynı zamanda bu yöntem bir değişkenin diğer bir değişken ya da değişkenler üzerindeki etkisi oryaya çıarmak amacıyla kullanılır (Büyüköztürk, 2016, s. 71-77). Yapılan araştırma; ergen boyun eğiciliği ile problem çözme yaklaşımları arasındaki ilişkiyi ortaya çıkarmayı ve ergen boyun eğiciliğinin problem çözme yaklaşımları üzerindeki etkisini sınamayı amaçlandığı için ilişkisel tarama yöntemi tercih edilmiştir.

\section{Evren - Örneklem}

Araştırma \% 56.7'si k1z, \% 43.3’ü erkek 763 ortaöğretim öğrencisi üzerinde gerçekleştirilmiştir. Çalışma grubunun sınıf, yaş ve okul türü değişkenlerine dağılımı Tablo 1'de gösterilmiştir.

Tablo 1. Örneklem Grubunun Demografik Özellikleri

\begin{tabular}{|c|c|c|c|c|c|c|c|c|}
\hline Cinsiyet & $N$ & $\%$ & Yaş & $N$ & $\%$ & Okul Türü & $N$ & $\%$ \\
\hline $\mathrm{K}_{12}$ & 433 & 56.7 & 14 & 135 & 17.7 & Anadolu Lisesi & 187 & 24.6 \\
\hline Erkek & 330 & 43.3 & 15 & 175 & 23.0 & Anadolu İmam Hatip & 178 & 23.3 \\
\hline Sinif & $\mathrm{N}$ & $\%$ & 16 & 201 & 26.3 & Mesleki Teknik Lise & 159 & 20.8 \\
\hline 1 & 199 & 26.1 & 17 & 173 & 22.7 & Güzel Sanatlar Lisesi & 77 & 10.1 \\
\hline 2 & 201 & 26.3 & 18 & 79 & 10.3 & Sosyal Bilimler Lisesi & 80 & 10.5 \\
\hline 3 & 202 & 26.5 & & & & Fen Lisesi & 82 & 10.7 \\
\hline 4 & 161 & 21.1 & & & & & & \\
\hline
\end{tabular}

\section{Veri Toplama Araçları}

Kişiler arası Problem Çöæme Envanteri (KPCCE): Envanter 18-30 yaşları arasındaki üniversite öğrencilerinde problem çözme yaklaşım ve becerilerini ölçmek için Çam ve Tümkaya (2007, s. 95-111) tarafindan geliştirilen bir araçtır. Her bir alt ölçek için elde edilen yüksek puan kişiler arası problem çözmeyle ilgili özelliğin yüksek olduğunu göstermektedir. Kişiler arası Problem Çözme Envanteri'nin (KPÇE) lise öğrencileri üzerinde geçerlik ve güvenirlik çalışmaları Çam ve Tümkaya (2008, s. 1-17) tarafindan yapılmıştır. KPÇE toplam 50 maddeden ve beş alt ölçekten oluşmaktadır. Bu alt ölçekler Probleme Olumsuz Yaklaşma, Yapıcı Problem Çözme, Kendine Güvensizlik, Sorumluluk Almama ve Israrcı-Sebatkâr Yaklaşımdır. Envanterin alt ölçek puanlarının Cronbach Alfa değerleri .67 ile .89 arasında; test- tekrar test korelasyon katsayıları ise .67 ile .84 arasında değişmektedir.

Ergen Boyun Ĕ̆iciliği Ölçeği: Ergen boyun eğiciliği ölçeği (ASBS) 12 maddeden oluşan ve yetişkin boyun eğiciliği ölçeğinin adaptasyonu ile oluşturulmuştur. (Gilbert ve Allan, 1994: 295-306; Allan ve Gilbert, 1997, s. 467-488). Yapılan bu araştırma için EBEÖ’nün faktör yapisını belirlemek amaciyla uygulanan açımlayıcı ve doğrulayıcı faktör analizleri sonuçlarına göre ölçek tek boyutlu bir yapı göstermektedir. EBEÖ'nün her bir madde için madde faktör yükleri .42 ile .65 arasında değişmektedir. Ölçeğin Cronbach Alpha iç tutarlılık katsayısı .76 olup test-tekrar test yöntemi ile ölçeklerden elde edilen güvenilirlik katsaylları .92 bulunmuştur. 
Veri toplama araçlarının uygulanabilmesi için öğrencilerin öğrenim gördükleri eğitim kurumlarından gerekli izin alınmıştır. Ayrıca araştırmanın amacı öğrencilere açıklanmış ve gönüllülük beyanı istenmiştir.

\section{Verilerin Analizi}

Araştırmada elde edilen veriler SPSS (Statistical Package for Social Sciences) for Windows 23.0 ve Amos 22.0 programı kullanılarak analiz edilmiştir. Verilerin normal dağllıma uygunluğunu sınamak amacıyla tanımlayıcı istatistik değerler ile çarpıklık ve basıklık değerleri, ölçeklerin güvenilirliğini test etmek amacıyla da iç tutarlık katsayıları hesaplanmıştır. Bu işlemlerden sonra araştırmanın hipotezleri yapısal eşitlik modellemesi yöntemi kullanılarak sınanmıştır. Bu amaçla kurulan modellerin uyum iyilik değerlerini belirlemek amaciyla CMIN/DF, GFI, AGFI, IFI, CFI ve RMSEA hesaplanmıss, daha sonra hesaplanan standart $\beta$, standart hata ve R2 değerleri üzerinden sonuçlar yorumlanmıştır.

Araştırma sorununun analizlerine geçmeden önce çalışma kullanılan değişkenlerin normal dağılımları ele alınmıştır. Normallikler çarpıklık ve basıklık katsayıları ile değerlendirilmiş ve Tablo 2'de sunulmuştur.

Tablo 2. Değiskeenlere Ait Normallik Değerleri

\begin{tabular}{lcc}
\hline Değişkenler & Çarpiklik & Basılk \\
\hline Ergen boyun eğiciliği & .935 & 1.268 \\
Problemlere olumsuz yaklaşım & .507 & -.319 \\
Yapıcı problem çözme & -.156 & -.145 \\
Kendine güvensizlik & 1.010 & 1.226 \\
Sorumluluk almama & .521 & -.266 \\
Israrc1-sebatkar yaklaşım & .021 & -.517 \\
\hline
\end{tabular}

Tablo 2'de görüleceği üzere değişkenlerin çarpıklık katsayıları .33 ile .44 arasında basıklık katsayıları da .34 ile .33 arasında değiştiği gözlenmiştir. Bachman'ın (2004) normal dağılım için önkoşul olan -2 ile +2 arasında olması gerektiği ifadesinden yola çıkılarak çalışmadaki tüm değişkenlerin normal dağılım sergiledikleri ifade edilebilir. Normal dağılımı görülen değişkenler kullanılarak araştırma öncelikle ön analizler gerçekleştirilmiştir. Ön analizlerde aracılık modeline dahil edilecek değişkenler arasındaki ilişkiler Pearson Korelasyon Katsayısı ile değerlendirilmiștir.

\section{Bulgular}

Araştırmada ergen boyun eğiciliğinin problem çözme yaklaşımları üzerindeki toplam etkisini sınamak amacıyla kurulan modele ilişkin hesaplanan uyum iyiliği değerleri Tablo 3’te gösterilmiştir.

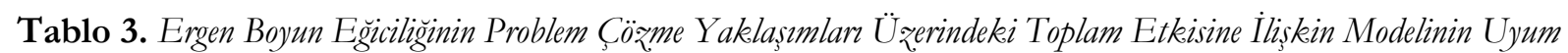
İyiliği Değerleri

\begin{tabular}{rcccccccc}
\hline CMIN & $D F$ & $p$ & $C M I N / D F$ & GFI & AGFI & IFI & CFI & RMSEA \\
\hline 4928,001 & 1819 & .000 & 2.709 & .914 & .901 & .886 & .875 & .047 \\
\hline
\end{tabular}

Modelde uyumu azaltan değişkenler belirlenerek, artık değerler arasında kovaryansı yüksek olanlar için yeni kovaryanslar oluşturulduktan sonra (e1-e2; e17-e18; e35-e39; e42-e44); X2/df = 2.709, GFI= .914, $\mathrm{AGFI}=.901, \mathrm{IFI}=.886, \mathrm{CFI}=.875$ ve RMSEA $=.047$ olarak hesaplanmıştır. Bu değerler verinin modele uyum sağladığına işaret etmektedir. Söz konusu modele ilişkin sonuçlar Şekil 1'de gösterilmiştir. 


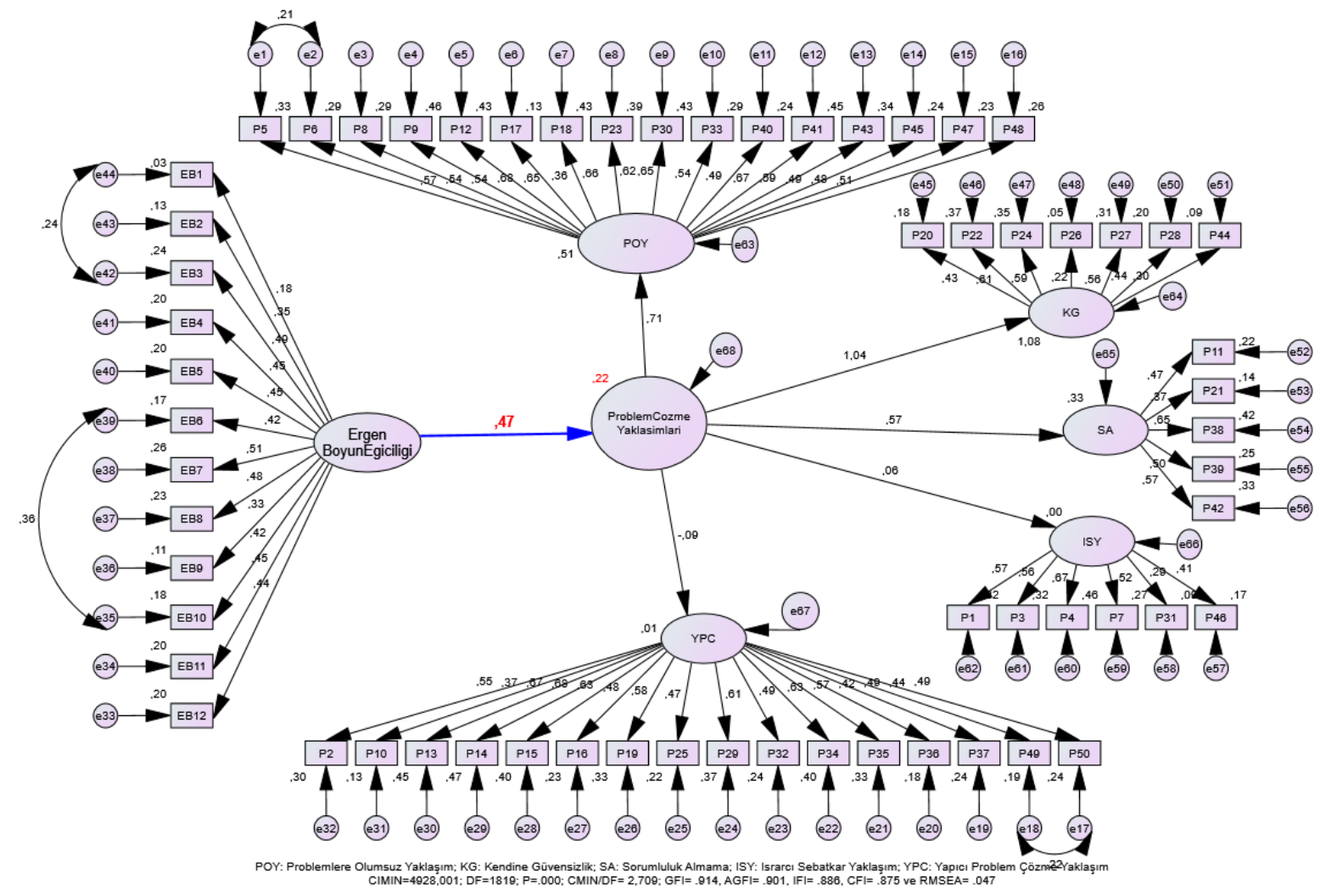

Şekil 1. Ergen Boyun Eğiciliğinin Problem Çöžme Yaklaşımlar Üz̧erindeki Toplam Etkisine İlişkin Model

Şekil 1 üzerinde gözlenen, ergen boyun eğiciliğinden problem çözme yaklaşımlarına giden yola ait standardize edilmiş beta, standart hata ve anlamllılı değerleri Tablo 4’te gösterilmiştir.

Tablo 4. Hipotez Testi Sonuçlan

\begin{tabular}{cccccc}
\hline Hipotez İlişkileri & $R^{2}$ & Standart $\beta$ & $\begin{array}{c}\text { Standart } \\
\text { Hata }\end{array}$ & P & Kabul/Ret \\
\hline Ergen Boyun Eğiciliği $\rightarrow$ Probleme Çözme Yaklaşımları. & .224 & .474 & .043 & $* * *$ & Kabul \\
\hline
\end{tabular}

Tablo 4'te görüldüğ̈u gibi, ergen boyun eğiciliği ile problem çözme yaklașımları arasında pozitif anlamlı ilişki gözlenmiştir $(\beta=.474 ; p<.05)$. Hesaplanan değerler ergen boyun eğiciliğinin problem çözme yaklaşımlarının anlamlı yordayıcısı olduğunu göstermektedir. Ergen boyun eğiciliği puanlarındaki bir birimlik artıs, problem çözme yaklaşımları puanlarında 0.5 yükselmeye yol açmaktadır. Bu değer; ergen boyun eğiciliğinin problem çözme yaklaşımları puanlarındaki toplam değişimin \%22'sini açıladığını göstermektedir $(\mathrm{R} 2=.224)$. Diğer bir ifade ile problem çözme yaklaşımlarının beşte biri ergenlerin boyun eğicilik özelliği tarafindan belirlenmektedir.

Ergen boyun eğiciliğinin problem çözme yaklaşımları üzerindeki etkisini daha ayrıntılı olarak ortaya koyabilmek amacıyla; problem çözme yaklaşımlarının alt boyutlarının dahil edildiği ikinci bir model kurulmuş ve sınanmıştır. Ergen boyun eğiciliğinin problem çözme yaklaşımları alt boyutları üzerindeki etkisini sınamak amacıyla kurulan modele ilişkin hesaplanan uyum iyiliği değerleri Tablo 5’te gösterilmiştir.

Tablo 5. Ergen Boyun Eğiciliğinin Problem Cözme Yaklassımlarmnn Alt Boyutlar Üzerindeki Etkisine İliskin Modelinin Uyum İyiliği Değerleri

\begin{tabular}{ccccccccc}
\hline$C M I N$ & $D F$ & $p$ & $C M I N / D F$ & GFI & AGFI & IFI & CFI & RMSEA \\
\hline 5209.892 & 1820 & .000 & 2.863 & .905 & .891 & .864 & .854 & .049 \\
\hline
\end{tabular}

Modelde uyumu azaltan değişkenler belirlenerek, artık değerler arasında kovaryansı yüksek olanlar için yeni kovaryanslar oluşturulduktan sonra (e1-e2; e17-e18; e35-e39; e42-e44); X2/df = 2.863, GFI= .905, AGFI $=.891, \mathrm{IFI}=.864, \mathrm{CFI}=.754$ ve RMSEA $=.049$ olarak hesaplanmıştır. Bu değerler verinin modele uyum sağladığına işaret etmektedir. Söz konusu modele ilişkin sonuçlar Şekil 2'de gösterilmiştir. 


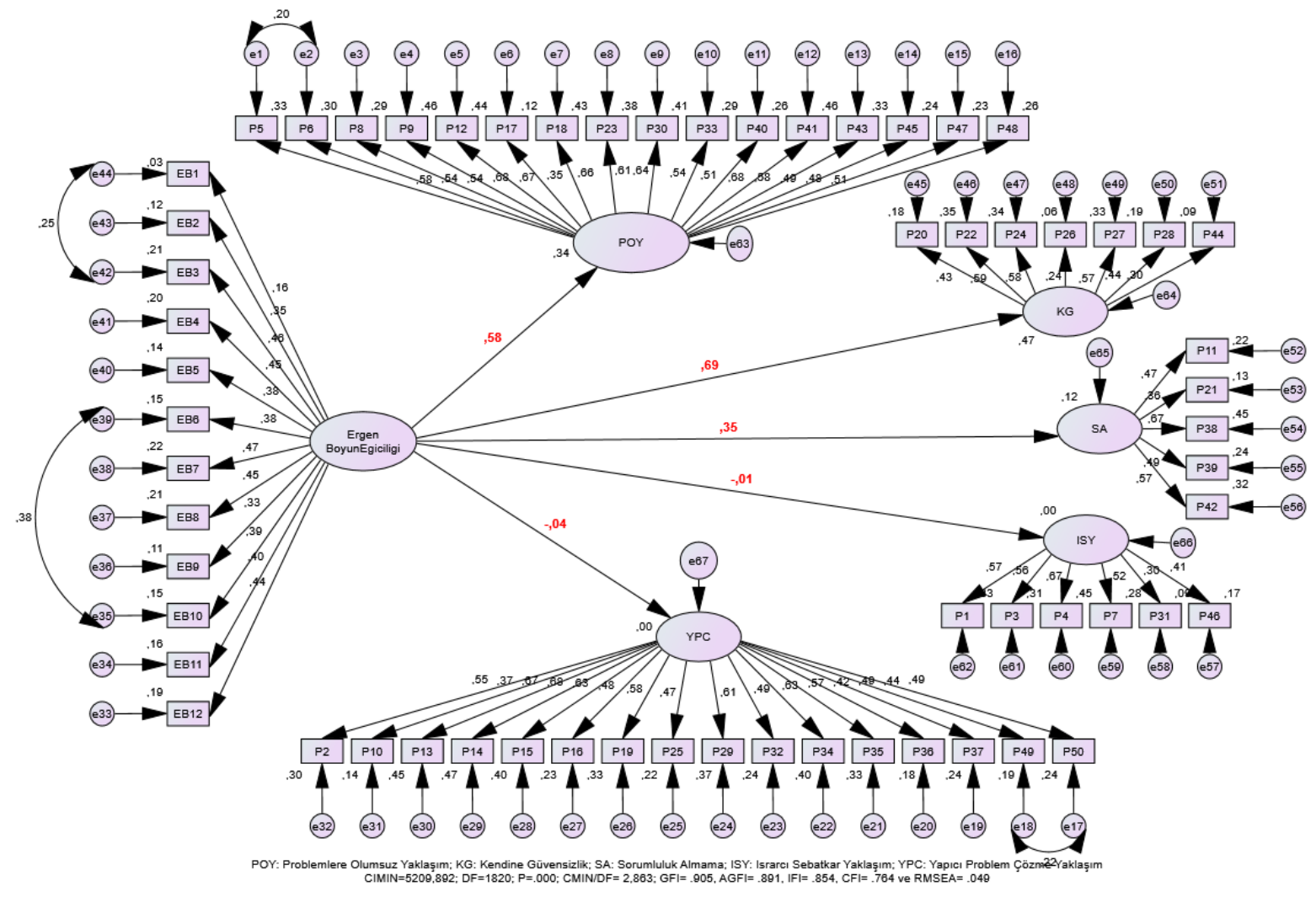

Şekil 2. Ergen Boyun Ë̆iciligünin Problem Çöz̆me Yaklaşımlarmm Alt Boyutlar Üzerindeki Etkisine Illiskin Model

Şekil 2 üzerinde gözlenen, ergen boyun eğiciliğinden problem çözme yaklaşımlarının alt boyutlarına giden yollara ait standardize edilmiş beta, standart hata ve anlamllık değerleri Tablo 6'da gösterilmiştir.

Tablo 6. Hipotez Testi Sonuclar

\begin{tabular}{lccccc}
\hline \multicolumn{1}{c}{ Hipotez Iliskileri } & $\boldsymbol{R}^{2}$ & $\begin{array}{c}\text { Standart } \\
\beta\end{array}$ & $\begin{array}{c}\text { Standart } \\
\text { Hata }\end{array}$ & $\boldsymbol{p}$ & Kabul/Ret \\
\hline Ergen Boyun Eğiciliği $\rightarrow$ Probleme Olumsuz Y. & .338 & .582 & .089 & $* * *$ & Kabul \\
Ergen Boyun Eğiciliğ $\rightarrow$ Kendine Güvensizlik & .472 & .687 & .078 & $* * *$ & Kabul \\
Ergen Boyun Eğicilĭg $\rightarrow$ Sorumluluk Almama & .123 & .351 & .062 & $* * *$ & Kabul \\
Ergen Boyun Eğiciliğ $\rightarrow$ Israrcı Sebatkar Yaklaşım & .000 & -.009 & .048 & .852 & Ret \\
Ergen Boyun Eğiciliği $\rightarrow$ Yapıcı Problem Çözme & .002 & -.039 & .050 & .379 & Ret \\
\hline
\end{tabular}

Tablo 6'da görüldüğü gibi, ergen boyun eğiciliği problemlere olumsuz yaklaşımın $(\beta=.582 ; p<.05)$, kendine güvensizliğin $(\beta=.687 ; p<.05)$ ve sorumluluk almamanın $(\beta=.351 ; p<.05)$ anlamlı yordayıcısıdır. Buna karşılık ergen boyun eğiciliğinin 1srarcı-sebatkar yaklaşımı $(\beta=-.009 ; p>.05)$ ve yapıcı problem çözmeyi $(\beta=-.039 ; p>.05)$ anlamlı düzeyde yordamadı̆̆1 saptanmışır. Özet bir ifade ile ergen boyun eğiciliğinin problem çözme yaklaşımları arasında olumsuz yaklaşımları temsil eden üç alt boyutu anlamlı düzeyde açıkladığı buna karşılık olumlu sayılabilecek iki problem çözme yaklaşımını anlamlı düzeyde açıklamadığ1 görülmüştür. Bununla birlikte ergen boyun eğiciliğinin problemlere olumsuz yaklaşım puanlarındaki değişimin \%34'ünü $(\mathrm{R} 2=.338)$, kendine güvensizlik puanlarındaki değissimin \%47'sini (R2= .472) ve sorumluluk almama puanlarındaki değişimin \%12'sini $(R 2=.123)$ açıkladığı da görülmüştür. 


\section{Tartı̧̧ma}

Yapılan araştırma ergenlerde boyun eğici davranışların onların problem çözme yaklaşımlarından üç tanesi (Probleme olumsuz yaklaşım, Kendine Güvensizlik, Sorumluluk almama) üzerinde anlamlı etkide bulunduğunu ortaya çıkarmıştır. Ergenlik döneminde bireyler içsel olarak birçok değişim yaşarken çevresindeki kişi ve gruplar ile de farklı etkileşim içerisine girebilmektedir. Bu etkileşimler sonucunda da kimi ergenler dışa dönük, atılgan, kendi haklarını savunabilen bireyler olurken bazıları da edilgen, haklarını savunamayan, boyun eğici bireyler olmaktadır. Boyun eğici davranışlar gösteren kişilerin kolayca girişimde bulunamamaları, kendine güvenlerinin çok düşük olması, ciddi sorumluluklar almaktan ve değişikliklerden kaçınmaları, insanlarla göz göze gelmekten sakınmaları ve öncü olamamalarıdır (Gilbert, Pehl ve Allan, 1994, s. 23-36). Bireyin toplum içinde yaşaması için uyma davranışı zorunludur. Kişiler arası ilişkilerde uyma davranışının sergilenmesinde boyun eğici davranışlar ve problem çözme yeteneği rol oynar. Literatür incelendiğinde Karabilgin ve Şahin (2012, s. 1536-1544) tarafindan gerçekleştirilen çalışmada da problem çözme becerilerinde kendini yetersiz gören öğrencilerin boyun eğici davranış da gösterdiği tespit edilmiştir. Smith, Meyers ve Delaney (1998, s. 541-548) boyun eğici kişilik özelliğine sahip bireylerin içinde bulunduğu durumu çözümsüz olarak algıladıklarını ya da kendi kaynaklarının çözüm için yeterli olmadığına inandıklarını belirtmiştir. Bu nedenle, bu tip bireylerin sorunları karşısında çözüm üretmek yerine, daha edilgen bir duruş sergilediklerini ortaya koymuşlardır. Bu durum problem çözmede 1srarcı-sebatkar yaklaşım sergileyen bir bireyin yani, bireyin problem yaşadığında problem çözülünceye kadar inatla üstüne gitmesi ve bir problemi çözerken, mutlaka bir sonuca ulaşmaya çalış̧ması ile zıtlık içermektedir ki gerçekleştirilen çalışmanın bulguları ile de paralellik sergilemektedir.

Probleme olumsuz yaklaşım kişilerarası problemlerde yaşanan çaresizlik, karamsarlık ve üzüntü gibi yoğun olumsuz duygu ve düşüncelerle ilgilidir. POY alt boyutunda ki bireyler yoğun olumsuz duygulanım sebebi ile genel olarak kendilerini problem çözmede yetersiz ve eksik görme eğiliminde olmaktadırlar. Ayrıca problem çözmede kendisini başarısız olarak değerlendirenlerin, daha fazla iç çatışmalı, kişilerarası ilişkilerde aşırı duyarlı, depresif ve obsesif davranışlara sahip oldukları tespit edilmiştir (Dixon, Heppner ve Anderson, 1991, s. 51-56). Boyun eğici davranış gösteren bireylerde gözlenen özellikler incelendiğinde; özgür davranamamaları sürekli içine kapanık bir tavır sergilemesi, liderlik davranışı gösterememesi, bir sorunla karşılaştığında bununla baş etmekte güçlük çekmesi, düşüncelerini özgürce ifade edememesi ve ciddi sorumluluklar almadan kaçması (Gilbert, Pehl ve Allan, 1994, s. 23-36) probleme olumsuz yaklaşan bireylerin kişilik özellikleri ile benzerlikler içermektedir.

Gelişimsel ve davranışsal teorilere göre (Gilbert, Allan ve Trent, 1995, s. 740-752) boyun eğme davranışı sergilemenin sebepleri arasında pasiflik ve depresyondan kaçınma isteği olduğu vurgulanmaktadır. Bu kaçınma davranışının pratik ve kişilerarası sorunların çözülmesini önlediği, devam eden kişilerarası çatışmaların alevlenmesine yol açtı̆̆, statü ve sosyal desteğin azalmasına yol açtığı ve ödüllendirici ve olumlu pekiştiriciyle teması azalttığı hipotezi vardır. Bu durum aynı zamanda bireylerin problem çözmede kendilerine duydukları güvendeki azlığ1 ve problemlerin çözümüne karşı sorumluluk almalarını etkileyebilecek etmenlerden olabileceği öngörülmektedir. Aynı zamanda bireyin problem çözerken sorumluluk almamasına, bir problemin çözümünde kendine güvenmemesine veya problem odaklı bir yaklaşım sergilemesine sebep olabilecek etmenlerin sebeplerinden olabilir.

Özellikle boyun eğici bireylerin disforik kişilik yapısına sahip olduğu düşünüldüğünde (Lyubomirsky, Tucker, Caldwell ve Berg, 1999, s. 1040-1060) bu tip bireylerin problem çözme yaklaşımlarının yapıcı şekilde gerçekleşmediği (Lyubomirsky vd., 1999, s. 1040-1060) problemleri ve problemlerin değerlendirilmesi de dahil olmak üzere özellikle baskı altındayken birkaç olası ve etkili çözüme güven duyulsa bile, sorunların çözülmesine yönelik isteklerinde azalma olduğu görülmektedir. Disforik kişilik yapısına sahip bireylerin bozulmuş problem çözme becerileri gösterdiğine ve kişiler arası problemlerde zayıf çözümler ürettiğine dair çalş̧malarda da mevcuttur (Lyubomirsky ve Nolen-Hoeksema, 1995, s. 176190; Strack, Blaney, Ganellen ve Coyne, 1985, s. 1076-1085). Bu durum aynı zamanda çalışmanın bulgularına paralel olarak, boyun eğici bireylerin problemin çözümüne sorumluluk üslenmemesinin sebepleri arasında gösterilebilir.

Alayanzındaki bu bilgiler ele alındığında çalışma sonucunda ortaya çıkan bulgunun beklendik yönde olduğu söylenebilir. Dolayısıyla ergen boyun eğiciliği kişiler arası problem çözme için bir risk faktörü olduğu sonucu çıkarılabilir.

Kişilerarası problemler ise çoğu zaman bireyin belirli bir davranışı göstermesi ile bu davranışı göstermesinin sonuçlarından korkması arasındaki çatışmayı yansıtır. Bu türden çatışmalar kısmen kişinin 
bağlanma ve kişilerarası ilişkileri öğrenme geçmişinden kaynaklanmaktadır (Horowitz, Rosenberg ve Bartholomew, 1993, s. 549-560). Heppner ve Krauskopfe (1987, s. 34-37) göre bireylerin problem çözme becerileri kişilerarası ilişkilerde oldukça önemli bir konudur. Problem çözme becerileri içsel ya da dişsal istekler ya da taleplere uyum sağlamak amaçlı, davranışsal tepkilerde bulunmak için bilişsel ve duygusal işlemleri bir hedefe yöneltmek olarak ele alınmıştır.

Boyun eğici olmayan, içsel denetimi güçlü bireyler bir problem yaşadıklarında problemin çözümüne odaklanarak, yapıcı bir şekilde problemi çözmeye çalışılar ve uzlaşmacı bir tavır sergileyerek olumlu ya da olumsuz duygularını ifade etmekten çekinmezler (Corcoran ve Mallinckrodt, 2000, s. 473-483; Feeney, 1995, s. 143-149; Kobak ve Hazan, 1991, s. 861-869; Shi, 2003). Hem kendilerine hem de diğerlerine ilişkin olumlu algıları olan bu kişiler kişilerarası problemlerinin çözümünde her iki tarafı da tatmin eden problem çözme davranışlarını benimsemektedir. Benzer şekilde, Zimmermann, Maier, Winter ve Grossmann (2001, s. 331-343) babalarıyla güvenli biçimde bağlanmış olan gençlerin zor problemlerle karşılaştıkları zaman arkadaşlarıyla işbirlikçi problem çözme davranışlarında bulunmayı tercih ettiğini, güvensiz biçimde bağlanmış olan gençlerin ise kendi başlarına problemi çözmeyi tercih edip, arkadaşlarıyla ortak bir çözüm arama yoluna gitmediğini gözlemişlerdir. Ayrıca Crowell vd. (2002, s. 679-683) yetişkinlerde güvenli bağlanma puanları yüksek olan bireylerin, güvenli üs algılları ile çiftler arası problem çözme becerileri arasında önemli ölçüde ilişkili olduğunu göstermişlerdir.

Ergenlerin yaşamsal döngüde kendi sorumluluklarını almaya başlamaları ve bağımsız olma istekleri karşılaştıkları problemleri benimsemek ve üstlenmekte güçlükler ortaya çıarmaktadır. Ergenlerin engelleri başarıyla aşması ve bu kritik dönemde karşılaştı̆ı sorunları etkili bir şekilde çözmesi için, başa çıkma becerileri olarak da tanımlanabilecek güçlü bir problem çözme becerisine sahip olması gerekir (Yılmaz, 2004, s. 56-60; Mamırova ve Yllmaz, 2019, s. 1153-1169). Ergenlik dönemi bireylerin karar verme ve problem çözme yeterlilikleri yönünden sınırlı yaşantılara sahip olduğu bir dönemdir. Ergenlerin karşılaştıkları çatışma ve sorunların onların etkin bir şekilde iş yapma ve çalışma kapasitelerini çoğu kez aşar. Ergenliğin genç yetişkinlikten önceki geçiş dönemi olduğu düşünüldügünde, ergenler bu dönemde sınırlı deneyimlere maruz kalmaktadırlar. Yaşantısal deneyimlerin sınırlı olması ergenler için karar verme ve problem çözme konularında ebeveyn kontrolünde olduklarını göstermektedir. Ergenlerin ebeveyn onayı olmadan birçok şeyi gerçekleştirememeleri (Oy veremezler, is arayamazlar, araba kullanamazlar vb.) belirsiz statülerini ve henüz olgunlaşamamış kimliklerinden dolayı ailesi, öğretmenleri ve toplumun diğer üyeleri çatışma yaşamalarına ve birçok problemle karsı karsıya kalmalarına sebep olmaktadır (Schvaneveldt ve Adams, 1983, s. 98-104).

Ergenlik dönemi ile birlikte dengeli ve uyumlu ilkokul çocuğunun yerine oldukça tedirgin, güç beğenen ve çabuk tepki gösteren bir genç gelir. Duygu durumundaki ani değişimler ortaya yeni problemler çıkartır. Birey çocuklukta herhangi bir problemle karşılaşı̆ı̆ında yetişkinlerden yardım alırken, toplum içinde kendine yer edinmeye çalışan ergen, problemlerin çözümünde yetişkinlerin müdahalesine set çeker ve kendi özel dünyasını oluşturmak için çaba sarf eder.

\section{Etik Beyan}

"Ergenlerde Gözlenen Boyun Eğiciliğin Onların Kişiler Arası Problem Çözme Yaklaşımları Üzerindeki Etkisi” başılılı çalışmanın yazım sürecinde bilimsel, etik ve alıntı kurallarına uyulmuş; toplanan veriler üzerinde herhangi bir tahrifat yapilmamış ve bu çalışma herhangi başka bir akademik yayın ortamına değerlendirme için gönderilmemiştir" şeklinde bir ibare eklenmelidir.

\section{Kaynakça}

Büyüköztürk, Ş. (2016). Sosyal bilimler için veri analizi el kitabı (22. Baskı). Ankara: Pegem akademi.

Corcoran, K. ve Mallinckrodt, B. (2000). Adult attachment, self-efficacy, perspective taking and conflict resolution. Journal of Counseling \& Development, 78(4), 473-483.

Crowell, J. A., Treboux, D., Gao, Y., Fyffe, C. Pan, H. ve Waters, E. (2002). Assessing secure base behavior in adulthood: development of a measure, links to adult attachment representations, and relations to couples' communication and reports of relationships. Developmental Psychology, 38, 679-693.

Çam, S. ve Tümkaya S. (2007). Kişiler Arası Problem Çözme Envanteri’nin (KPÇE) Geliştirilmesi: Geçerlik ve güvenirlik çalışmas1. Türk Psikolojik Danısma ve Rebberlik Dergisi, 28(3), 95-111.

Çam, S. ve Tümkaya, S. (2008). Kişiler arası problem çözme envanteri lise öğrencileri formu'nun geçerlik ve güvenirlik çalışması. Uluslararası İnsan Bilimleri Dergisi, 5(2), 1-17.

Dixon, W. A., Heppner, P. P. ve Anderson, W. P. (1991). Problem-solving appraisal, stress, hopelessness, and suicide ideation in a college population. Journal of Counseling Psychology, 38(1), 51-56. 
Dönmez, B., Demirtaş, H. (2009). Lise öğretmenlerinin boyun eğici davranışlarına ilişkin algıları. Kastamonu Ĕgitim Dergisi, 1(2), 445-456.

Feeney, J. A. (1995). Adult attachment and emotional control. Personal Relationships, 2(2), 143-159.

Gander, M. J. ve Gardiner, H. W. (1998). Cocuk ve ergen gelisimi. Ankara: İmge Kitabevi Yayınları.

Gilbert, P. ve Steven A. (1994). Assertiveness, submissive behaviour and social comparison. British Journal of Clinical Psychology, 33, 295-306.

Gilbert, P., Allan, S. ve Trent, D. R. (1995). Involuntary subordination or dependency as key dimensions of depressive vulnerability? Journal of Clinical Psychology, 51(6), 740-752.

Gilbert, P., Pehl, J. ve Allan, S. (1994). The phenomenology of shame and guilt: An empirical investigation. British Journal of Medical Psychology, 67, 23-36.

Heppner, P. P. ve Krauskopf, C. J. (1987). An information processing approach to personal problem solving. The Counseling Psychologist, 15(3), 34-37.

Horowitz, L. M., Rosenberg, S. E. ve Bartholomew, K. (1993). Interpersonal problems, attachment styles, and outcome in brief dynamic psychotherapy. Journal of Consulting and Clinical Psychology, 61(4), 549-560.

Isaksen, S. G. ve Aerts, W. S. (2011). Linking problem-solving style and creative organizational climate: An exploratory interactionist study. The International Journal of Creatwnty \& Problem Solving, 21(2), 7-38.

Jacobson, N. ve Margolin, G. (1979). Marital therapy: Strategies based on social learning and behavior exchange principles. New York: Brunner/Mazel. pp. 81-90.

Karabilgin, S. Ö. ve Şahin, H. (2012). Tip fakültesine yeni başlayan öğrencilerin problem çözme becerilerine ilişkin algılarının ve boyun eğici davranış durumlarının değerlendirilmesi. Türkiye Klinikleri T⿰p Bilimleri Dergisi, 32(6), 1536-1544.

Karasar, N. (2005) Bilimsel araştırma yöntemi. Ankara: Nobel Yayın Dağıtım.

Koç, M., Bayraktar, B. Ç. ve Çolak, T. S. (2010). Üniversite öğrencilerinde boyun eğici davranışlarının çeşitli değişkenler açısından incelenmesi. Sakarya Üniversitesi Sosyal Bilimler Enstitüsü Dergisi, 28(1), 257-280.

Lyubomirsky, S. ve Nolen-Hoeksema, S. (1995). Effects of self-focused rumination on negative thinking and interpersonal problem solving. Journal of Personality and Social Psychology, 69(1), 176-190.

Lyubomirsky, S., Tucker, K. L., Caldwell, N. D. ve Berg, K. (1999). Why ruminators are poor problem solvers. Clues from the phenomenology of dysphoric rumination. Journal of Personality and Social Psychology, 77(5), 1041-1060.

Mackinnon, A., Henderson A. S. ve Andrews, G. (1992). Parental 'affectionless control' as an antecedent to adult depression: A risk factor redefined. Psychological Medicine, 23, 135-140.

Mamırova, C. ve Yilmaz, H. (2019). İtaatkârlar daha mı mutlu? Pozitif psikoloji perspektifinden boyun eğicilik. Manas Sosyal Arastermalar Dergisi, 8(1), 1153-1169.

Milgram, S. (1974). Obedience to authority: An experimental view. USA: HarperCollins.

Schvaneveldt, J. D. ve Adams, G. R. (1983). Adolescents and the decision-making process. Theory into Practice, 22(2), 98-104.

Smith, J. E., Meyers, R. J. ve Delaney, H. D. (1998). The community reinforcement approach with homeless alcoholdependent individuals. Journal of Consulting and Clinical Psychology, 66, 541-548.

Strack, S., Blaney, P. H., Ganellen, R. J. ve Coyne, J. C. (1985). Pessimistic self-preoccupation, performance deficits, and depression. Journal of Personality and Social Psychology, 49(4), 1076-1085

Tekin, M. ve Filiz, K. (2008). Beden eğitimi ve spor yüksekokullarının antrenörlük eğitimi ve spor yöneticiliği bölümlerinde öğrenim gören öğrencilerin umutsuzluk ve boyun eğici davranış düzeylerinin çeşitli değişkenlere göre incelenmesi. Spormetre Beden Ë̈itimi ve Spor Bilimleri Dergisi, 6(1), 27-37.

Tuzcuoğlu, S. ve Korkmaz, B. (2001). Psikolojik danışma ve rehberlik öğrencilerinin boyun eğici davranış ve depresyon düzeylerinin incelenmesi. Marmara Üniversitesi, Eğitim Bilimleri Dergisi. 14, 135-152.

Tümkaya, S., Çelik, M. ve Aybek, B. (2011). Lise öğrencilerinde boyun eğici davranışlar otomatik düşünceler umutsuzluk ve yaşam doyumunun incelenmesi. Cukurova Üniversitesi Sosyal Bilimler Enstitüsü Dergisi, 20(2), 77-94.

Yılmaz, N. (2004). Öfke ile başa çıkma eğitiminin ve grupla psikolojik danışmanın ergenlerin öfke ile başa çıkabilmeleri üzerindeki etkisi. Yaynlanmamıs Doktora Tęi. Hacettepe Üniversitesi.

Zimmermann, P., Maier, M., Winter, M. ve Grossmann, K. E. (2001). Attachment and adolescents' emotion regulation during a joint problem solving task with a friend. International Journal of Behavioral Development, 25, 331343.

\section{EXTENDED ABSTRACT}

Three types of behavior characteristics are observed in humans. There is submissive behavior at one extreme while there is aggressive behavior at the other extreme. In the middle of these two types of behavior, there is a behavior pattern that protects and claims its rights. Submissive behavior is also addressed as passive and withdrawn behavior (Tuzcuoğlu, \& Korkmaz, 2001; Dönmez, \& Demirtaş, 2009). Submissive behavior is defined as the set of a personality trait that cares not to hurt others, tries to please everyone, tends to be benevolent, hesitates to say no, has difficulty in expressing the undesired situations and showing anger, needs constant approval, cannot assert opinions and claims and can be observed with similar behaviors (Gilbert, \& Steven, 1994). It was stated that the most important source of 
people's showing submissive behavior is the authoritarian, disciplined, supervised, oppressive, and extremely restrictive parent attitudes.

Interpersonal problem was defined as a contradiction that emerges when the behavioral desires or expectations occurring in the relationship of two or more individuals are restrained (Jacobson and Margolin 1979). In this context, interpersonal problem-solving can be defined as a cognitive interpersonal process that aims to eliminate conflicts by defining and discovering the solution that is acceptable or satisfactory for all relevant parties. The individual, who is aware of the interpersonal problem, uses different ways to get rid of the tension caused by the objective desired to be achieved with the present situation. Many researchers have classified these methods, which are named as interpersonal problemsolving approaches, in various forms. In this research, the classification made by Çam and Tümkaya (2007) was taken as the baseline. The authors dimensioned interpersonal problem-solving as negative approach to the problem, lack of self-confidence, unwillingness to take responsibility and insistentpersistent approach.

In this research, the effect of submissive behaviors observed in adolescents on their problem-solving approaches mentioned above was examined. For this purpose, answers were sought to the following questions.

1. To what extent does adolescent submissiveness explain the totality (generality) of problem-solving approaches?

2. To what extent does adolescent submissiveness explain the sub-dimensions of problem-solving approaches (Negative Approach to the Problem, Constructive Problem-Solving, Lack of Self-Confidence, Unwillingness to Take Responsibility and Insistent-Persistent Approach)?

Since the aim was to reveal the relationship between adolescent submissiveness and problem-solving approaches and to examine the effect of adolescent submissiveness on problem-solving approaches, relational screening method was preferred in the research. The research was conducted on 763 secondary school students $(56.7 \%$ female and $43.3 \%$ male). The data collected through the Interpersonal ProblemSolving Inventory and Adolescent Submissiveness Scale were analyzed with structural equation modeling.

A positively significant relationship was found between adolescent submissiveness and problemsolving approaches $(\beta=.474 ; p<.05)$. The calculated values reveal that adolescent submissiveness is a significant predictor of problem-solving approaches. A unit increase in adolescent submissiveness scores leads to 0.5 increase in the scores of problem-solving approaches. This value reveals that adolescent submissiveness explains $22 \%$ of the total change in the scores of problem-solving approaches $(\mathrm{R} 2=.224)$. In addition, adolescent submissiveness is a positive predictor of negative approach to problems $(\beta=.582$; $p<.05)$, lack of self-confidence $(\beta=.687 ; p<.05)$ and unwillingness to take responsibility $(\beta=.351 ; p<.05)$. However, it was seen that adolescent submissiveness did not significantly predict insistent-persistent approach $(\beta=-.009 ; p>.05)$ and constructive problem-solving $(\beta=-.039 ; p>.05)$. In summary, it was seen that adolescent submissiveness significantly explained three sub-dimensions representing negative approaches among problem-solving approaches, while it did not explain two problem-solving approaches which could be considered as positive. Furthermore, it was seen that adolescent submissiveness explained $34 \%$ of the change in the scores of negative approach to problems ( $\mathrm{R} 2=.338$ ), $47 \%$ of the change in the scores of lack of self-confidence $(\mathrm{R} 2=.472)$ and $12 \%$ of the change in the scores of unwillingness to take responsibility $(\mathrm{R} 2=.123)$.

The research revealed that submissive behaviors in adolescents had a significant effect on three (negative approach to the problem, lack of self-confidence, unwillingness to take responsibility) of their problem-solving approaches. While individuals experience many inner changes during adolescence, they may be involved in different interactions with people and groups around them. As a result of these interactions, some adolescents become extroverted and assertive individuals who can defend their rights, while others become passive and submissive individuals who cannot defend their rights. Individuals, who exhibit submissive behaviors, cannot easily interact, have low level of self-confidence, avoid taking responsibility and avoid changes, avoid making eye contact with people, and cannot be pioneers (Gilbert, Pehl and Allan, 1994). Adaptation is essential for an individual to live in the society. Submissive behaviors and problem-solving ability play a role in the exhibition of the adaptation behavior in interpersonal relationships. When the literature was examined, in the study conducted by Karabilgin and Şahin (2012), it was determined that the students who found themselves inadequate in their problem-solving skills also 
exhibited submissive behaviors. Smith, Meyers and Delaney (1998) stated that the individuals with submissive personality traits perceived their situation as unsolvable or believed that their own resources were not sufficient for a solution. Therefore, they revealed that such individuals exhibited a more passive attitude rather than producing solutions to their problems. This situation is in contradiction with the fact that an individual, who exhibits insistent-persistent behaviors in problem-solving, tries to reach a conclusion absolutely until the problem is solved and this also shows parallelism with the findings of this research. 